BMJ Open

Sport \&

Exercise

Medicine

\section{From big data mining to technical sport reports: the case of inertial measurement units}

To cite: Rojas-Valverde D Gómez-Carmona CD, Gutiérrez-Vargas R, et al. From big data mining to technical sport reports: the case of inertial measurement units. BMJ Open Sport \& Exercise Medicine 2019:5:e000565. doi:10.1136/ bmjsem-2019-000565

Accepted 29 May 2019

\section{Check for updates}

(C) Author(s) (or their employer(s)) 2019. Re-use permitted under CC BY-NC. No commercial re-use. See rights and permissions. Published by BMJ.

${ }^{1}$ Centro de Investigación y Diagnóstico en Salud y Deporte, Escuela Ciencias del Movimiento Humano y Calidad de Vida, Universidad Nacional de Costa Rica, Heredia, Costa Rica ${ }^{2}$ Physical Activity and Sport Department, University of Extremadura, Caceres, Spain ${ }^{3}$ BioVetMed \& SportSci Research Group, Department of Physical Activity and Sport, Universidad de Murcia, Murcia, Spain

Correspondence to Dr Daniel Rojas-Valverde; drojasv@hotmail.com

\section{ABSTRACT}

The inertial measurement units (IMU) are instruments used to quantify the external load of athletes; they are increasingly common in assessing team and individual sports. This type of instruments has several sensors, such as accelerometers, gyroscopes and magnetometers; this allows access to a large amount of information and analysis possibilities. Due to the complexity of synthesising this data, it is necessary to create a flow for collecting, analysing and presenting the collected data in a simple way and present it as quickly as possible to the technical staff. This report aims to present new methods of reduction of the data and propose a new approach method for the analysis of the IMU's outcomes.

\section{BIG DATA IN SPORTS}

The rise of cloud computing and storage, virtual mapping and localisation, and artificial intelligence in decision-making are examples of how technology is impacting our day-to-day activities. ${ }^{1}$ This evolution in technology has impacted sports and the increase in measurement has led to abundant data that then need to stored, kept safe and analysed. The large amount of information collected digitally and stored in large quantities has been termed 'big data'. 2 In sports, big data provide an opportunity to further understand the technical, tactical and physiological behaviour of athletes.

Current dynamics of sport has undergone a great evolution as a consequence of

\section{Key points}

- Big data analysis derived from inertial measurements has become a great challenge in sports.

- Reduction data techniques, such as cluster analysis, have been proposed as data simplification method.

- Assessment's final report should be concise and rapidly available to practitioners to make opportune decisions.

the high frequency of competitive events and the need for players to recover quickly between those events. This posts a great challenge for the technical staff of team sports in areas such as the measuring training load and guiding training volume and even load in competition (rotation in and out of the team in team sports, minutes played, events competed in for individual sports, etc). In the last two decades, the scientific community has endeavoured to develop technology that meets the demands of high performance in sport, hence providing useful information for the monitoring and control of internal and external loads.

These changes in competition and training dynamics have caused major changes in the way in which athletes are monitored and information is collected, analysed and presented to technical staff and athletes alike. In this viewpoint, we discuss new tools that are valid, reliable and precise, ${ }^{4}$ and that
A

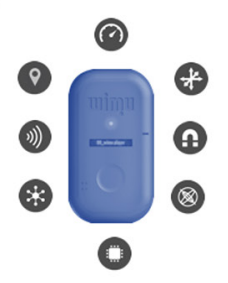

B

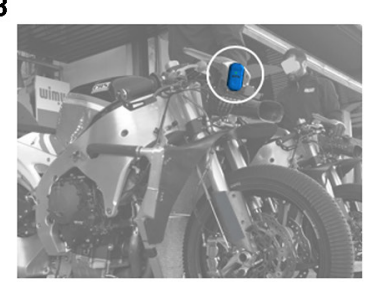

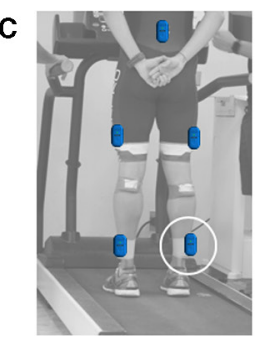

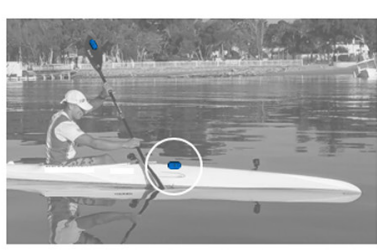

Figure 1 (A) Inertial measurement unit's applications in sports. Analyses in (B) speed motorcycling: pilot's internal and external loads, (C) running: multidevices external load running and (D) canoeing: stroke mechanic and canoe oscillation. 

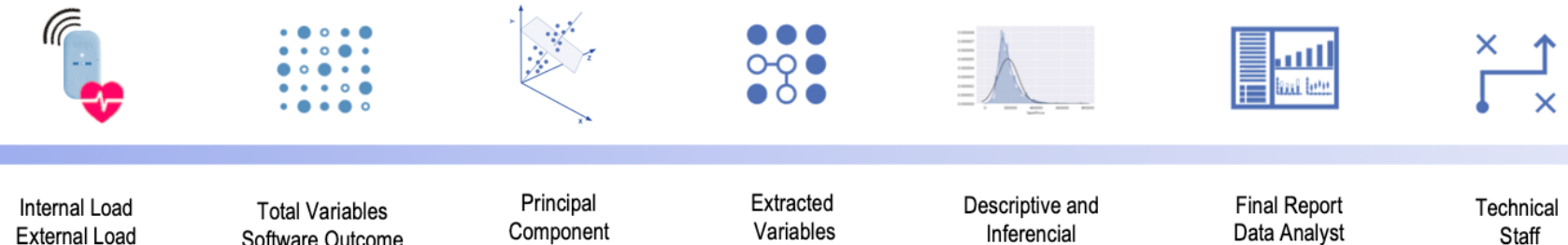

External Load

Total Variables

Software Outcome

Principal
Component
Analysis

Extracted

Variables

Descriptive and
Inferencial
Analysis

Final Report

Data Analyst

Technical

Decision-making

Figure 2 From data collecting to technical staff reporting flow chart.

aid practitioners (eg, coaches, medical staff) who work in sport. To select which specific instrument to use, the practitioner should answer the following questions $s^{5}$ : Is it easy to use? Which is the final outcome? How will the data be presented to the athlete? How much time is required for the analysis? What is the cost?.

\section{INERTIAL MEASUREMENT UNITS IN SPORTS}

New technologies for real-time tracking of external and internal loads variables include, but are not limited to, video capture systems, global and local positioning tracking systems, digital smartphone applications, and biochemical and portable metabolic analysers. Inertial measurement units (IMU) (see figure 1) have been developed and the companies have improved their systems in collection and analysis of information.

IMU technology has been applied in some disciplines, such as occupational health, transport industry, medicine and rehabilitation among others. In sports, it is a relatively new technology for the monitoring of time motion and kinematics, through external and internal loads in team and individual sports. One of the biggest challenges when using these technologies is the management of a large amount of information collected from up to 250 variables and high sampling frequencies. These devices provide a large amount of data per second; the information must be collected, processed, analysed and reported; the process is challenging, and certain procedures must be considered (see figure 2).

\section{VARIABLES SELECTION AND EXTRACTION METHODS}

Due to a large amount of data collected in a very short time, the uncertainty about which information is the most relevant, companies have created software that simplify the outcomes and it's understanding of the data. Nonetheless, there is doubt surrounding the fact that which variables explain behaviour better and therefore, the athlete's performance. Due to this uncertainty, methodologies for analysis and simplification of data have been implemented, such as the principal component analysis as a cluster analysis.

These data reduction techniques have been used with success in sports. ${ }^{6}$ These statistical techniques allow researchers to select and extract the variables that explain the variance of a certain group of data and hence, the total behaviour of a team or teams during a day of training, week, months or even a complete season. It is necessary to perform this analysis as individualised as possible explain personalised data and apply it consequently. $^{7}$

The possibility of reducing a big group of correlated variables in a series of uncorrelated ones that explained a high percentage of total group variance allows to understand athletes load in a simple way, ${ }^{8}$ considering normally less than 10-15 variables and simplifying reporting and communication.

\section{THE ROLE OF DATA ANALYSTS AND SPORT SCIENTISTS}

In addition, the technology and data processing advances lead to the necessity of new staff roles for the management and monitoring of team's fundamental data. The data analyst, for example, is in charge of providing information and reports at the end of each training or game day related to the performance of the athletes and on the other hand, sports scientist collaborates with the medical body in the regulation of the loads using the outcomes of these information analyses. Criticism, teamwork, high adaptability, technical-tactical sport understanding and synthesis capacity could be some of the requirements to assume these new staff roles. These new staff members must have the ability to analyse information, conduct academic research, develop reports and provide timely feedback to technical staff to collaborate to achieve the athlete's optimal performance.

To further improve performance, the future of sports analysis related to physical, tactical and technical monitoring will demand simplifying data collection and analysis regarding most important and influential factors of a specific sport.

Contributors DR-V: first draft and conceptual idea of the manuscript, and reviewing, editing and writing of the manuscript. CDG-C, RG-V and JP-0: editing, reviewing, writing and development of the manuscript.

Funding The authors have not declared a specific grant for this research from any funding agency in the public, commercial or not-for-profit sectors.

Competing interests None declared.

Patient consent for publication Not required.

Provenance and peer review Not commissioned; externally peer reviewed.

Open access This is an open access article distributed in accordance with the Creative Commons Attribution Non Commercial (CC BY-NC 4.0) license, which permits others to distribute, remix, adapt, build upon this work non-commercially, and license their derivative works on different terms, provided the original work is properly cited, appropriate credit is given, any changes made indicated, and the use is non-commercial. See: http://creativecommons.org/licenses/by-nc/4.0/.

ORCID iD

Daniel Rojas-Valverde http://orcid.org/0000-0002-0717-8827 


\section{REFERENCES}

1. Verhagen EA, Clarsen B, Bahr R. A peek into the future of sports medicine: the digital revolution has entered our pitch. Br J Sports Med 2014;48:739-40.

2. Murdoch TB, Detsky AS. The inevitable application of big data to health care. JAMA 2013;309:1351-2.

3. Stein M, Janetzko $H$, Seebacher $D$, et al. How to make sense of team sport data: from acquisition to data modeling and research aspects. Data 2017;2.

4. Balsalobre-Fernández C, Glaister M, Lockey RA. The validity and reliability of an iPhone APP for measuring vertical jump performance. J Sports Sci 2015;33:1574-9.
5. Parrington L, Giblin G, Tor E. Sensoria special edition on contemporary perspectives on applied sports science: technology and performance: editorial. Sensoria 2016;12:1-2.

6. Gløersen Øyvind, Myklebust H, Hallén J, et al. Technique analysis in elite athletes using principal component analysis. J Sports Sci 2018;36:229-37.

7. Svilar L, Castellano J, Jukic I, et al. Positional differences in elite Basketball: selecting appropriate Training-Load measures. Int $J$ Sports Physiol Perform 2018;13:947-52.

8. Casamichana D, Castellano J, Gómez Díaz A, et al. Looking for complementary intensity variables in different training games in football. J Strength Cond Res. In Press 2019. doi:10.1519/ JSC.0000000000003025 